\title{
VESTÍGIOS DA PRESENÇA DAS IDEIAS EDUCACIONAIS DE JOHN DEWEY EM UMA ESCOLA NORMAL PAULISTA NAS DÉCADAS DE 10 E 20 DO SÉCULO XX
}

\author{
Michele Varotto ${ }^{1}$ \\ Alessandra Arce Hai ${ }^{2}$ \\ Universidade Federal de São Carlos - UFSCar
}

\section{RESUMO}

O presente artigo propõe-se a investigar como as ideias educacionais de John Dewey foram apropriadas na formação de professores no interior da Antiga Escola Normal Secundária de São Carlos-SP. Para compreender esses preceitos buscou-se estudar e analisar os artigos publicados na Revista da Escola Normal de São Carlos (feita sob a responsabilidade dos docentes da instituição, entre 1916-1923), na qual se destacaram pela apropriação e discussão direta das concepções educacionais de John Dewey. Os resultados obtidos por esse estudo demonstram a presença e apropriação de John Dewey no interior da instituição, bem como permitem a compreensão do movimento das ideias pedagógicas de John Dewey no contexto brasileiro.

Palavras-chave: História das Ideias Pedagógicas; John Dewey; Escola Normal; Formação de professores; Escola Nova.

\section{TRACES OF THE PRESENCE OF JOHN DEWEY EDUCATIONAL IDEAS IN A NORMAL SCHOOL IN SÃO PAULO DECADES OF 10 AND 20 OF THE TWENTIETH CENTURY}

\begin{abstract}
The aim of this article is to investigate how John Dewey's educational thoughts were appropriate in teacher's education in Antiga Escola Normal Secundária de São Carlos-SP. In order to do that one studied and analyzed all the articles published in Revista da Escola Normal de São Carlos (produced by the teachers of that school between the years 19161923). As a result this research points out that John Dewey ideas were present and thought in this school.

Keywords: History of Pedagogy; John Dewey; Escola Normal; Teacher Education; Progressive Education.
\end{abstract}

\section{Introdução}

O presente artigo $^{3}$ objetiva apreender e analisar como as ideias educacionais de John Dewey foram apropriadas no interior de uma instituição educacional paulista. Neste sentido, o referido estudo, aqui apresentado, busca demonstrar a partir da análise dos trabalhos publicados na "Revista da Escola Normal de São Carlos" pelos docentes da instituição entre 1916-1923, quais as ideias educacionais de John Dewey se fizeram presentes em seus artigos, procurando-se ao mesmo tempo encontrar pistas e rastros da relação destas referências ao autor e sua teoria com as primeiras publicações do mesmo, as quais se encontram organizadas em duas coleções: "The Early Works (1882-1898)" e "The Middle Works (1899-1924)". 
A metodologia de pesquisa utilizada para a realização deste estudo encontra-se pautada no campo História das Ideias Pedagógicas. Entendendo-se ideias pedagógicas, segundo Saviani (2007, p. 15), como: “(...) as ideias educacionais consideradas, porém, não em si mesmas, mas na forma como se encarnam no movimento real da educação orientando e, mais do que isso, constituindo a própria substância da prática educativa." Os passos metodológicos seguidos, desta forma, centraram-se nas cinco categorias estruturadas por Saviani (2007): a-caráter concreto do conhecimento históricoeducacional (que consiste na reconstrução, por meio de ferramentas conceituais, das relações e determinações que caracterizam a educação como fenômeno concreto; demonstrando o quanto o objeto de estudo está expresso na complexidade das relações e determinações presentes na sociedade de sua época); $b$ - perspectiva de longa-duração (para se captar as mudanças (anteriores e posteriores) e o movimento orgânico (estrutural): é necessário abranger um período longo da história); $c$-olhar analítico-sintético no trato das fontes (refere-se ao esforço em compreender o objeto de pesquisa em seu tempo, revelando as complexidades da sociedade da época e sua abrangência); $d$-articulação do singular e do universal (trata-se de detectar qual o grau em que o nacional e o local constituem expressões de tendências que se impõem internacionalmente); e-atualidade da pesquisa histórica (trata-se, então, da consciência de que o presente está fortemente enraizado no passado e, logo, para entendê-lo é necessária à compreensão de suas raízes).

O presente artigo está organizado em três itens: num primeiro é apresentada uma discussão geral sobre a Escola Normal Secundária de São Carlos - SP, destacando sua fundação e a importância dessa instituição para a educação brasileira; em seguida apresenta-se uma breve análise sobre as primeiras discussões veiculadas por John Dewey, a ênfase será dada em como o autor pensava a educação logo no início de suas produções; no terceiro item, por fim, procura-se demonstrar a presença das ideias educacionais de John Dewey no interior da Escola Normal Secundária de São Carlos-SP, por meio dos intelectuais que o divulgaram nesta instituição.

\section{Escola Normal Secundária de São Carlos ${ }^{4}$ - SP e sua Produção Educacional}

São Carlos, fundada em 1857, no interior do Estado São Paulo, possuiu um expressivo desenvolvimento econômico, proporcionado pela lavoura de café, e pela consequente possibilidade de exportação demarcada pela construção das estradas de ferro em 1884. Estes fatores garantiram a São Carlos, o título de "Atenas Paulista". O seu prestígio a partir da Proclamação da República em 1889, só veio a aumentar. Desta forma, os investimentos possibilitados por essa crescente produção, fizeram com que a cidade pudesse usufruir de grandes realizações, o que contou com a participação das elites cafeeiras, também, com a dos imigrantes italianos que vinham trabalhar nas fazendas de café e que acabavam por se instalarem na cidade. Linha telefônica, energia elétrica, bondes, comércios, foram tais elementos que aos poucos dominaram o município, visando, primeiramente, prover as elites cafeeiras; de tal modo que os referidos aspectos se ramificaram e trouxeram novas possibilidades à cidade, a qual procurou, também, seguir os padrões da denominada belle époque que contaminava o país.

No campo educacional, São Carlos - SP, assim, pôde usufruir de um ensino condizente às propostas e iniciativas educacionais do Estado de São Paulo. Como um dos pioneiros na difusão do ensino, principalmente do primário, o Estado, segundo Nagle (2009), após a Proclamação da República, passou a defender uma escola de acesso obrigatório, universalizada, baseada em uma educação com um programa enciclopédico e enriquecido, de caráter estatal. 
O Estado de São Paulo, com isso, foi um dos pioneiros na difusão do ensino primário, o que foi mais acentuado com a criação, em 1890, dos grupos escolares ${ }^{5}$. Essa nova modalidade de ensino representou uma das mais importantes inovações no processo educacional brasileiro.

Esse ambiente de euforia com a educação presente no Estado de São Paulo não passou impune a cidade de São Carlos-SP, levando-a a dar os primeiros passos conforme Neves (2007), na sua transformação em um centro escolar. Desta forma, em 1901, funda-se no município o primeiro grupo escolar, na Praça Coronel Salles, denominado de Paulino Carlos; tendo o segundo sua fundação somente em 1919, denominado de Eugênio Franco que se instalou junto a Estação no prédio que antes fora ocupado pela Escola Normal. Desse momento em diante, a cidade contou com a criação de vários grupos: em 1922, o Grupo Escolar Arlindo Bittencourt; em 1934, o Grupo Escolar Bispo Dom Gastão e o Grupo Escolar Professor Luiz Augusto de Oliveira. Assentavam-se, assim, as bases para a formação da população são-carlense.

Entretanto, para que houvesse a formação de professores aptos a lecionar nas instituições e com base nas propostas disseminadas pela República Brasileira, o Ensino Normal ganhava destaque no Estado. Segundo Monarcha (2009), as Escolas Normais tiveram sua fundação engendrada às urgências históricas da formação de uma sociedade de classes e em processo de uma urbanização acelerada.

Dentro deste contexto ocorre a instalação da Escola Normal Secundária de São Carlos-SP, em 1911. Considerada como um marco no processo cultural da cidade, em uma época em que poucos municípios poderiam usufruir de uma escola desse porte, tal empreendimento significou o desenvolvimento do município, já que congregava em seu interior salas de aula com jovens oriundos da classe média e da elite, abrangendo uma vasta região e que trouxe a São Carlos-SP a visão de um núcleo polarizador, segundo Truzzi (2007, p. 115)

Além disso, a fixação em São Carlos de lentes ilustres para o magistério nessa instituição conferia à cidade uma certa efervescência cultural, um certo ambiente propício à criação de clubes literários, reuniões científicas, etc., tão a gosto do pensamento especulativo e da roupagem vistosa dos intelectuais de então, de imaginação cultivada e leituras francesas.

A instalação de uma Escola Normal Secundária em São Carlos-SP em uma posição central no município permitiu que o mesmo pudesse exalar o progresso e contribuir para o desenvolvimento do local. No entanto, mesmo antes da promulgação da lei criadora da escola, o secretário de Agricultura e obras públicas, Dr. Carlos Botelho, resolveu anteciparse e determinou a construção de um prédio destinado a ela, colocando em 2 de abril de 1908 a pedra do edifício, no terreno adquirido do coronel Manoel Antonio da Cunha, nas proximidades da estação da estrada de ferro. Porém, durante meses o prédio permaneceu desocupado.

Pelo decreto número 1998, de 4 de fevereiro de 1911, em conformidade com a lei número 1245, de 30 de dezembro de 1910, sendo presidente do Estado, o Sr. Dr. Manoel Joaquim de Abulquerque Lins e Secretário do Interior, o Dr. Carlos Augusto Pereira Guimarães, a Escola Normal Secundária de São Carlos-SP foi fundada. Tendo como primeiro diretor, o Dr. João Chrysostomo Bueno dos Reis Junior, e respectivamente para as cadeiras $^{6}$ de: português, latim, francês e aritmética e álgebra, os professores: Dr. João Augusto Pereira Junior; Prof. Juvenal de Azevedo Penteado e Prof. João Lourenço Rodrigues.

A Escola rapidamente tornou-se referência cultural na cidade por meio de suas publicações, conferências, círculos de estudos, sessões culturais. E também de suas 
publicações como as revistas: Revista Excelsior ${ }^{7}$ (composta e organizada pelos normalistas da instituição) e a Revista da Escola Normal de São Carlos (organizada pelos docentes da instituição).

A Revista da Escola Normal de São Carlos, no entanto, fundada pelos professores desta instituição tinha como objetivo divulgar de acordo com a comissão de sua redação: “(...) trabalhos sobre pedagogia, critica de livros, ensaios philosophicos e outros que possam contribuir para argumentar entre os moços o amor pelos estudos" (Revista Escola Normal de São Carlos, 1916, p. 1). Suas edições datam de 1916 a 1923, com uma ou duas publicações em um mesmo ano, as quais se encontram guardadas no acervo da instituição. Seus números abrangem os mais diferentes conteúdos, como: discussões sobre a melhor configuração para o ensino normal até metodologias de ensino; desenvolvimento da criança; História do Brasil; configuração de sala de aula; Geografia; linguagem; medicina escolar; higiene; exaltação da profissão docente; organização das atividades do professor e veiculação de conteúdos, por exemplo: desenho, geometria, física, química, língua portuguesa, francês, etc. Um fator de grande relevância, que poderíamos chamar de "fator comum" em todos os números dessa Revista, são as discussões fortes e pertinentes sobre: o patriotismo, nacionalismo; a exaltação a bandeira brasileira, as suas riquezas, a sua língua, seus "heróis"; seu povo; são fortemente veiculadas por elas; as quais são justificadas pelos próprios autores como uma forma de não se perder os costumes, a cultura brasileira, mediante ao processo imigratório que se fazia presente no período.

Para a constituição desse estudo o enfoque recai na referida Revista pela possibilidade trazida de encontrar-se em suas páginas referências ao trabalho de John Dewey. Antes, porém, de adentrarmos na discussão de quais concepções foram apropriadas e os lentes que se destacaram por essa veiculação, faz-se importante discutir alguns dos preceitos de John Dewey presentes em suas primeiras obras, as quais foram reunidas em dois volumes por um grupo de educadores norte-americanos da Sourthen Illinois University Press, e receberam a denominação de "The Early Works (1882-1898)", "The Middle Works (1899-1924)"8. A escolha destas obras deu-se porque a cronologia de publicação aproxima-se da publicação da Revista, ao mesmo tempo algumas das obras reunidas nestes volumes são citadas nos textos analisados.

\section{As Ideias Educacionais de John Dewey entre 1882-1924}

John Dewey nasceu em 20 de outubro de 1859, na cidade de Burlington, no Estado de Vermont - EUA. Formado inicialmente em Fisiologia na Universidade de Vermont, segundo Cunha (2002), despertou-se para a filosofia e com isso, em 1882 ingressou na John Hopkins University de Baltimore, na qual fez Doutorado. Inicia sua carreira profissional da Universidade de Michigan em 1884, como professor de filosofia. Permaneceu em Michigan até 1894, quando é nomeado diretor do Departamento de Filosofia, Psicologia e Educação da Universidade de Chicago, onde dirige também a Escola-Laboratório Anexa à Universidade. Em 1905, foi para a Teachers College na Universidade Columbia, na qual permaneceu até 1930. Essas experiências profissionais somadas às novas ideias educacionais que circulavam pelo mundo permitiram a Dewey o desenvolvimento de suas concepções educacionais e a proposição de preceitos inovadores ao contexto educacional.

Dewey (1976) afirma que estamos acostumados a olhar a escola de um ponto de vista muito individualista, como se somente existisse a relação entre professor e aluno, ou professor e pais. Para o autor, além do foco voltado ao progresso feito individualmente pela criança, seja no seu desenvolvimento físico; nas suas habilidades de ler e escrever; seu 
crescimento no conhecimento de história, geografia; seja no aperfeiçoamento dos hábitos de prontidão, ordem e tarefas industriais; há a necessidade de se ampliar a visão sobre o papel da escola na vida do sujeito.

Segundo o autor, o que os pais almejam para seus filhos, é o mesmo que a comunidade quer para todas as crianças. Isto significa que toda sociedade vê a escola como uma agência que forma seus membros, de acordo com os valores almejados para se apresentar um novo futuro. Assim, Dewey (1976) destaca a necessidade de um novo movimento educacional que considere a vida social para que por meio de inovações educacionais se possam trazer novas condições à sociedade.

Neste sentido, a educação volta-se à observação da experiência da criança sobre o mundo, seus interesses e atividades que expressam suas manifestações e permitem o uso de sua mente. Conhecer o mundo da criança, impulsioná-la para descobri-lo e aprimorar suas funções deve ser o foco do trabalho do professor.

Além desse aspecto, Dewey (2008c) destaca a necessidade de interpretação dos interesses inerentes à criança. $\mathrm{O}$ interesse, segundo o autor, é um aspecto importante a ajudar o desenvolvimento da criança. No entanto, essa apenas irá descobrir-se a partir do contato com os objetos e pela energia devotada a estes, isto significa que somente na experiência real com os instrumentos que a criança irá descobrir-se, revelando seus interesses, por isso, o papel do professor está em ler essas manifestações e aprimorá-las.

A escola como instituição, para Dewey (2008c), deveria simplificar a vida social, de modo a reduzi-la a sua forma embrionária. Nesta concepção defendida pelo autor, o professor não pode ser um impositor de ideias ou formador de hábitos, mas um membro dessa comunidade que amplia os horizontes infantis auxiliando a criança no seu processo de disciplinamento.

Dewey (1976) afirma que o conhecimento formal vinculado a lições e meras informações deve ser substituído pelas ocupações diárias que a criança já possui e, estão presentes no seio familiar. Tais ocupações se tornam grandes objetos de aprendizagem para as crianças, porque através delas, as mesmas podem aprender o conhecimento científico de acordo com as necessidades que encontram em seus afazeres cotidianos, sem contar que a criança já adquire os valores fundamentais para vida social, encontrando sua função e desenvolvendo-se de forma significativa, ou seja, o conhecimento que ela adquirirá terá para ela um sentido em sua vida. Desta forma, a criança será capaz de interpretar as situações sociais e adaptar-se para conviver com diferentes personalidades, bem como entrará em contato com as atividades que envolvem o meio no qual se encontra inserida.

A introdução, nesta direção, de ocupações sociais em suas várias formas na escola, irá contribuir para a renovação de todo o espírito escolar. Essa, para Dewey (1976), é a chance da criança desde sua mais tenra idade de associar-se à vida, desenvolver seus hábitos, ao invés de sua existência estar fundada apenas em possibilidades de uma vida abstrata, com referências remotas ao que poderá ser feito no futuro. Essa é a grande faceta da comunidade em miniatura, de uma sociedade embrionária, a qual possibilita o curso ordenado, contínuo e fundamental da instrução, isto é, “(...) it is this liberation from narrow utilities, this openness to the possibilities of the human spirit that makes these pratical activities in the school allies of art and centres of science and history." (DEWEY, 1976, p. 13).

Isso não significa que a criança desenvolverá apenas as ocupações sem que estas estejam relacionadas ao conhecimento científico, pelo contrário, a cada desempenho de um ato os fatores que o formam, bem como sua composição, manipulação, história farão parte dos estudos da criança para que ela possa melhor compreendê-los. O professor, neste processo, para o autor, é essencial, pois será ele que fornecerá os subsídios necessários 
para que a criança possa desempenhar determinadas funções. Seja com sugestões ou novas questões, cabe ao educador incitar novas descobertas na criança.

Desta forma, nota-se que a introdução das ocupações no interior escolar, bem como da natureza do estudo elementar das ciências, de artes, de história, gerarão mudanças essenciais no interior da educação, na relação entre aluno-professor, na disciplina, introduzindo mais atividade e expressividade; elementos que são fundamentais para evolução social. Para isso, é preciso fazer de cada escola uma sociedade embrionária, ativa e com diferentes tipos de ocupações que reflitam na ampla vida social, e que estejam permeadas do espírito das ciências, artes e história. Quando a escola introduz e treina cada criança como membro de uma pequena comunidade, segundo Dewey (1976), inunda-o com o espírito do serviço, e providencia-o os instrumentos efetivos para direcionar-se; tem-se a intensa e melhor garantia de uma larga sociedade digna, amável e harmoniosa.

Esse tipo de trabalho escolar calcado, portanto, nas ocupações opera, de acordo com o autor, na esfera dos interesses da criança levando-a a apreciar e querer realizar o trabalho escolar. Portanto, a criança desenvolve seu interesse pela escola e pelo trabalho nela desenvolvido através da correlação que pode fazer entre esse e sua vida, pois, os interesses da criança não são barrados dentro da escola, mas aprofundados em seu trabalho, despertando novos interesses e, assim, continuamente proporcionando o descobrir-se enquanto individuo pertencente a um coletivo social.

Desta forma, é que Dewey (1976) defende a conexão da escola com a vida, com a experiência da criança, desde sua relação com o ambiente familiar, porque o que a criança aprende em casa é levado para a escola e ampliado, fazendo com que essa retorne e amplie em sua vida diária. Deste modo, nota-se que a experiência não está isolada dos conhecimentos, ela liga-se a geografia, a arte, a literatura, às ciências, a história; todos os estudos estão ligados à vida em uma forma concisa e não separadamente como fora feito.

"Aprender fazendo" é o slogan que o autor afirma ser fundamental para o trabalho escolar, porque a criança só aprende pela prática, a qual fornece maior facilidade para essa desenvolver e compreender os estudos que englobam o conhecimento. Os estudos, assim, representam a possibilidade de desenvolvimento da criança pelas experiências que fazem parte de seu dia-a-dia, a única diferença é que a escola organiza essas experiências de forma que possibilite a criança encontrar os conhecimentos de história, geografia, ciências, aritmética, dentro das mesmas, já que para o autor, uma educação que ignora o processo vital se torna algo abstrato à criança, e consequentemente, reprime os impulsos e ações dela.

Dewey (1976), desta forma, admite que seu desejo é de que a escola seja um lugar onde a criança realmente viva, que viva em experiência e que assim, possa encontrar o significado no mundo que a rodeia. A vida da criança é tão importante quanto à de um adulto, por isso é preciso considerar sua relevância e as possibilidades de seu desenvolvimento na vida presente e não focar-se apenas nos fatores que poderão formá-la.

Quando adultos, ou seja, no futuro, quando se apela para as ocupações e suas formas de utilização dos materiais, instantaneamente volta-se para o trabalho com a mente da criança, com a cultura social, com o conhecimento acumulado, com a ciência em todas as suas formas, o que enriquece e ordena a vida infantil. Portanto, para o autor, somente quando natureza e sociedade puderem viver em uma sala de aula, quando as formas e brinquedos de aprendizagem forem subordinados a substância da experiência, então existirá a oportunidade de identificação e de cultura, os quais são a senha para a democracia.

Estas ideias de Dewey sucintamente apresentadas aqui nos levam a perguntar: a Revista da Escola Normal de São Carlos traria estes preceitos impressos em suas páginas? 


\begin{tabular}{|c|c|c|c|c|}
\hline Artigos & Autor & Edição & Data & Páginas \\
\hline "A Escola Brazileira" & João & Ano II/ & $11 / 12 / 1917$ & $77-83$ \\
\hline
\end{tabular}

Ou os lentes da escola nos levariam a uma reinterpretação destes preceitos? Estariam estes ideais presentes e sendo divulgados no interior de uma Escola antes mesmo do Manifesto dos Pioneiros da Educação Nova? Teria esta Revista um caráter pioneiro na divulgação do ideário educacional de Dewey? A estas questões procuramos responder no próximo item.

\section{Apropriações e Discussões das Ideias Educacionais de John Dewey no interior da Escola Normal Secundária de São Carlos-SP}

A leitura e análise dos artigos, presentes no periódico, trouxe uma dificuldade a falta de referências diretas nos escritos, seus artigos e provas trabalham com temas gerais, e são poucos os que citam diretamente o autor ou corrente a partir da qual fundamentam seus escritos. Desta forma, focamo-nos apenas nos trabalhos que citaram diretamente Dewey, tomando-os como referência na constituição das discussões. Pela leitura e análise dos periódicos e avaliações da instituição, apenas a Revista da Escola Normal de São Carlos (1916-1923) apresenta artigos que citam diretamente John Dewey em suas publicações, destacando-se, no entanto, nos escritos de apenas dois lentes: João Augusto de Toledo e Carlos da Silveira.

Com base no levantamento realizado na Revista da Escola Normal de São Carlos, pode-se constatar que muitos de seus artigos trabalham em um mesmo título com diversos conceitos de John Dewey, dentre ao quais podemos citar: aprender fazendo; cooperação; ocupações manuais ou trabalhos manuais; sociedade em miniatura ou comunidade embrionária; experiência; interesse; ensino ativo; educação ligada ao meio social; consideração das aptidões do sujeito; formação da moral. Conceitos estes, que aparecem difundidos nos artigos dos dois lentes, como demonstra a Tabela 1.

Dentre os conceitos de John Dewey citados e defendidos pelos lentes, podemos notar uma exaltação a uma nova forma de se conceber o ensino, assumindo uma postura adversa a todas as concepções anteriores a esta, como: um ensino centralizado no professor, como se esse fosse o detentor de todo saber; aprendizagem apenas pela observação, sem que a criança participe manuseando os objetos; o estudo calcado em livros apenas; o foco na memorização; são alguns dos conceitos que encontramos fortemente condenados por Toledo e Silveira em seus escritos nesse periódico, vistos como mecânicos, desinteressantes e que não proporcionam uma aprendizagem efetiva por parte da criança. 


\begin{tabular}{|c|c|c|c|c|}
\hline & Toledo & Número 3 & & \\
\hline "Hereditariedade e Educação" & João & Ano III/ & Junho de & $12-24$ \\
& Toledo & Número 4 & 1918 & \\
\hline "Aprendizado Activo" & João & Ano IV/ & Junho de & $37-54$ \\
& Toledo & Número 6 & 1919 & \\
\hline "Aprendizado Activo II" & João & Ano IV/ & Dezembro & $30-48$ \\
& Toledo & Número 7 & de 1919 & \\
\hline "Os ideaes nacionaes e as escolas & João & Ano V/ & Junho de & $3-20$ \\
elementares" & Toledo & Número 8 & 1920 & \\
\hline "Questões de Ensino Normal" & Carlos da & Ano V/ & Junho de & $32-57$ \\
Silveira & Número 8 & 1920 & \\
\hline "Bases para a elaboração e & João & Ano V/ & Novembro & $33-49$ \\
execução de um programma de & Toledo & Número 9 & de 1920 & \\
história em nossas escolas & & & & \\
primárias e normais" & & & & \\
\hline "Assumptos Escolares (cultura & Carlos da & Ano VI/ & Junho de & $34-46$ \\
cívica-sugestões) & Silveira & Número 10 & 1921 & \\
\hline "Introdução aos programmas de & João & Ano VI/ & Dezembro & $64-70$ \\
psychologia, pedagogia e & Toledo & Número 11 & de 1921 & \\
methodologia das Escolas & & & & \\
Normaes Paulista" & & & & \\
\hline
\end{tabular}

Tabela 1: Artigos da Revista da Escola Normal de São Carlos que apresentam alguns dos conceitos de John Dewey

Fonte: Elaborado pelas autoras.

João Augusto de Toledo e Carlos da Silveira, portanto, são dois nomes que se destacam nesse levantamento pela incidência de John Dewey em seus escritos e, principalmente, pela defesa de uma educação nacional calcada nas propostas trazidas pelo autor. Desta forma, faz-se necessário, mesmo que em poucas palavras, destacar um pouco sobre a trajetória e produções desses educadores, o que permitirá compreender melhor os fatores que influenciaram na apropriação das ideias educacionais de John Dewey em suas produções.

\section{CARLOS DA SILVEIRA}

Nascido em 21 de junho de 1883, em Silveiras, Carlos da Silveira, ainda quando adolescente, mudou-se para Queluz. De 1900 a 1903 se diplomou na Escola Normal da Praça, e em 1904 iniciou o magistério na Escola Isolada da Freguesia do O'. Em 1907, torna-se diretor das Escolas Reunidas da Avenida Paulista, na qual permanece até 1909, ano em que além de se tornar diretor do Grupo Escolar da Avenida Paulista, conclui a graduação em Direito pela Faculdade de Direito de São Paulo. Tais experiências o levam a lecionar na comissão do Estado de Sergipe em 1911.

Pelo levantamento feito na documentação da Escola Normal Secundária de São Carlos-SP, em 1912, Carlos da Silveira aparece como Secretário da instituição, função na qual permaneceu até 06 de Fevereiro de 1913, pois no dia 10 do mesmo mês e ano, encontra-se sua primeira assinatura como docente da Escola Normal Secundária de São Carlos-SP, à frente da cadeira de Pedagogia e Educação Cívica, assumindo seu lugar na secretaria Waldomiro Caleiro.

Em 14 de fevereiro do mesmo ano o Professor João Augusto de Toledo assume as aulas de Psicologia Experimental. No entanto, em 1914 a cadeira de Psicologia 
Experimental, Pedagogia e Educação Cívica ${ }^{9}$, se consolida, ramificando-se em duas, ficando uma sob a responsabilidade de Carlos da Silveira e outra com João Augusto de Toledo $^{10}$. Esta cadeira perpetua na Escola Normal Secundária de São Carlos-SP de 1915 a 1920.

A partir de 1921 não se encontra mais o nome do Professor Carlos da Silveira na Escola Normal Secundária de São Carlos-SP, apenas na Revista da Escola Normal da instituição, na qual o lente publica até 1923, data que finaliza as edições da mesma. Segundo Melo (1954), em 1921, o professor assume como lente substituto a cadeira de Psicologia e Pedagogia, diretor em comissão e professor de didática na Escola Normal do Braz; e em 1925 torna-se professor interino de Psicologia e Pedagogia na Escola Normal da Praça e professor de Psicologia e Pedagogia na Escola Normal de Campinas-SP, na qual permanece até 1928, quando dirige-se ao cargo de inspetor da Escola Normal Livre do Colégio de Santa Inês. Em 1930, já como redator-chefe da Revista Educação, concilia esse trabalho com o ensino de Pedagogia e Psicologia no Curso Normal do Instituto Pedagógico, e em 1933, torna-se lente catedrático de História da Civilização, no Instituto de Educação, última titulação e cargo que Carlos da Silveira exerce.

Ainda segundo este autor, o lente Carlos da Silveira durante sua trajetória teve a participação em: comissões examinadoras para o provimento do cargo de professores e inspetores nas Escolas Normais; representante do Estado de São Paulo na: III Conferência Nacional de Educação, na Reunião da Federação das Sociedades de Educação realizada no Rio de Janeiro e, na VI Conferência Nacional de Educação que aconteceu no Ceará. Como escritor teve seus trabalhos publicados: na Revista "O Início" do Liceu de Artes e Ofícios; "Névoas" do Centro Normalista; "O País" do Rio de Janeiro; "Revista do Ensino" e Revista "Educação"; e nos jornais: "Estado de São Paulo", "Jornal do Comércio", "Diário de São Paulo", "Diário da Noite", "Correio Paulistano". Revistas e jornais nos quais publicou seus estudos sobre genealogia, história, pedagogia, psicologia, ensaios e até mesmo biografias.

\section{JOÃO AUGUSTO DE TOLEDO}

João Augusto de Toledo ${ }^{11}$ nasceu em 12 de maio de 1879, em Tietê, São Paulo. Formou-se em 1900, na Escola Complementar de Itapetininga, momento em que, segundo Monarcha (2011), o triunfo inicial estava na aquisição do diploma de professor primário. No ano seguinte, o então professor preliminar, recebe o título de professor-adjunto do grupo escolar de Serra Negra, tornando-se diretor da instituição no mesmo ano, um cargo que, de acordo com Pinheiro (2009), marcara a distinção e honra, como um representante legítimo do governo. Em 1908, João Toledo foi transferido para o Grupo Escolar "Coronel Joaquim Augusto de Salles", localizado em Rio Claro-SP. No qual permaneceu até 14 de fevereiro de 1913, data que marca a assinatura do educador no Livro de Compromisso da Escola Normal Secundária de São Carlos-SP, como lente da 12a cadeira: Psicologia Experimental, Pedagogia e Educação Cívica.

Inicialmente, a cadeira assumida por João Toledo recebe a denominação nos Livros Pontos da Escola Normal Secundária de São Carlos-SP de: Psicologia Experimental. Com as mudanças da nomenclatura das disciplinas em 1914 no Livro Ponto da instituição, João Toledo aparece à frente da $12^{\mathrm{a}}$ cadeira, de: Psicologia Experimental, Pedagogia e Educação Cívica.

Cadeira esta, na qual permanece até 1921, quando é removido para a Escola Normal de Campinas-SP, para reger a cadeira de: Psicologia e Pedagogia desta instituição. Entretanto, no mesmo ano foi designado a cadeira de: Prática Pedagógica, ficando a de 
Psicologia e Pedagogia para Sylvio de Moraes Sales. Essa instituição é a última em que o educador leciona, assumindo na mesma o cargo de Diretor, e em 1939, já aposentado, João Toledo, vem a falecer.

Um educador ativo nos debates e estudos de sua época, veiculando suas ideias em diversas revistas dentre as quais destacam-se: Revista da Escola Normal de São Carlos (1916-1923); Revista de Ensino; e a Revista de Educação. Mesmo deixando de lecionar na Escola Normal de São Carlos-SP em 1921, continua publicando artigos no periódico da instituição, totalizando uma gama de trabalhos até o encerramento da mesma em 1923.

João Toledo pode ser exaltado como uma figura de grande nome na educação paulista, passando por todos os graus do magistério, difundiu suas ideias e participou ativamente dos degraus de transformação do ensino normal, baseado na Psicologia para melhor compreensão da criança. Suas obras desenvolvem essas ideias e permitem, segundo Monarcha (2011), aprofundar nas ideias que se movimentaram no início do século XX na educação brasileira.

Assim, a partir da breve contextualização sobre a trajetória educacional de Carlos da Silveira e João Augusto de Toledo, podemos notar a importância dos mesmos na Educação Brasileira. Ativos nos debates, publicações e disseminação de concepções no início do século XX, ambos os educadores a frente da cadeira de Psicologia Experimental, Pedagogia e Educação Cívica, na antiga Escola Normal Secundária de São Carlos destacam-se pela apropriação e veiculação de ideias que se fizeram presentes em sua época e nos permitem compreender a forma de incorporação das mesmas no bojo da formação de professores.

\section{3- VESTÍGIOS DA PRESENÇA DAS IDEIAS EDUCACIONAIS DE JOHN DEWEY NA REVISTA DA ESCOLA NORMAL DE SÃO CARLOS-SP (1916-1923).}

A partir da leitura e análise dos artigos publicados na Revista da Escola Normal de São Carlos-SP, evidencia-se a presença das ideias educacionais de John Dewey, em grande parte das publicações do professor João Augusto de Toledo e, em alguns trabalhos do professor Carlos da Silveira.

Notamos a inferência dos mesmos preceitos defendidos por Dewey em suas primeiras obras nos trabalhos desses lentes. Enquanto o professor Carlos da Silveira parece se debruçar mais sobre a ideia da inserção de "ocupações ou trabalhos manuais" no interior da escola, afirmando que:

(...) o espírito esclarecido de JOHN DEWEY que promove um systema de trabalho manual (systema social) (...) As occupações judiciosamente escolhidas despertam os instinctos das creanças, e os dirigem para as vistas modernas, fazendo-os passar pelas phases de consciência que uma raça superior atravessou para chegar ao estado civilizado: tal é o alvo e o methodo da educação pela escola, segundo formula o professor DEWEY. (SILVEIRA, 1921a, p. 41).

E ainda, destaca a figura de Dewey como promotor de uma nova forma de conceber o ensino, e vê na promoção de trabalhos manuais a oportunidade da criança desenvolver-se plenamente, afirmando que o autor, como seus sucessores, “(...) esboçaram os meios de execução, isto é a forma manipulatoria e classica apropriada para levar estas noções ao espírito das creanças." (SILVEIRA, 1921a, p. 41).

João Augusto de Toledo, também, apresenta em suas discussões a necessidade do trabalho com as ocupações manuais, pois afirma que essas são imprescindíveis para o desenvolvimento do pensamento da criança, ou seja, para o lente, as atividades das 
crianças exercitam-se em virtude das necessidades reais, “(...) o mesmo facto se dá com o pensamento normal, ensina DEWEY (School and Society)" (TOLEDO, 1919a, p. 48). Conforme o autor, o pensamento surge da necessidade de refletir sobre o meio de dominar uma dificuldade, conduz o indivíduo a fazer planos, projetar resultados e decidir sobre seus passos.

Segundo o lente, já que a educação é o resultado do trabalho manual com a mente, quer dizer, educar-se é se preparar para resolver de modo racional as dificuldades encontradas na vida. Por conseguinte, mesmo realizando qualquer experiência "(...) a criança deve pôr o máximo de sua attenção no que está fazendo" (TOLEDO, 1919a, p. 51). O ponto fundamental, desta discussão, está em equilibrar o prático com o intelectual, para que a inteligência acompanhe os movimentos executados na experiência.

A premissa do "aprender fazendo" ou "learning by doing" como afirma Dewey; torna-se recorrente tanto em seus trabalhos quanto nos do professor João Augusto de Toledo. Carlos da Silveira a destaca como “(...) o verdadeiro modo de aprendizagem, já estão fartos de saber todos os que reflectem sobre coisas de ensino." (SILVEIRA, 1921a, p. 42). E ainda, acrescenta que a grande regra que deve permear o ensino é: “(...) aprender a fazer, FAZENDO; ao que eu acrescentarei - e para FAZER". (SILVEIRA, 1921 a, p. 45). Já João Toledo afirma que as “(...) qualidades práticas começam a desenvolver-se quando a escola conhece e executa o axioma do "APRENDER A FAZER, FAZENDO"”. (TOLEDO, 1917, p. 78); e ainda a destaca como fundante da prática educativa: “(...) já nos vamos hoje convencendo de que, em todas as actividades que reclamam aprendizado, só se aprende a fazer, fazendo" (TOLEDO, 1919a, p. 43).

Da mesma forma com que esses preceitos são defendidos pelos lentes, "experiência; ensino ativo; educação ligada ao meio; desenvolvimento das aptidões; interesse; moral; cooperação; e sociedade em miniatura"; são discutidas e apropriadas pelos educadores. João Augusto de Toledo (1919a) afirma que o professor deve ser um guia da criança para que essa "(...) realizando experiências e exercitando acções semelhantes ás que terá de realizar e exercitar no seio da sociedade" (TOLEDO, 1919a, p. 47). E ainda, exalta a necessidade da escola organizar-se como uma “(...) sociedade em miniatura, pois assim a transição entre ambas será mínima a passagem será quasi imperceptível.” (TOLEDO, 1919b, p. 47-48). Já que o papel da escola é preparar “(...) para a vida e não para a escola" (SILVEIRA, 1921 a, p. 44).

Considerar as especificidades da criança, seus interesses é algo assumido e defendido por João Augusto de Toledo: “(...) querer tratar todos com iguais maneiras é absurdo como o é querer calçar a todos pela mesma fôrma” (TOLEDO, 1918a, p. 14); ou ainda, que "(...) o apparecimento do desejo de aprender qualquer gênero de conhecimento implica a aptidão de espírito para a sua acquisição e necessita della para o seu progresso." (TOLEDO, 1919b, p. 31).

As proximidades entre as discussões de João Augusto de Toledo com base nos preceitos de Dewey são ainda intensificadas quando nos deparamos com o artigo "Bases para a elaboração e execução de um programma de história em nossas escolas primárias e normais" "12, no qual aquele apresenta pontos semelhantes às discussões feitas por John Dewey em um dos tópicos de sua obra "The School and Society" escrita por ele em 1900. O item "The aim of history in elementary education", apresenta os pontos fundamentais para o ensino de história às crianças. Segundo Dewey (1976), a história deve ser demonstrada a criança como um processo formador da vida social, de modo a centrarse principalmente, nos modos de vida e organização. Simplificada e desligada de "nomenclaturas", Dewey (1976), defende o ensino de história com base na dinâmica das 
vivências do sujeito e das práticas que estiveram imersas em seu cotidiano, de modo que a permita identificar-se com a sua vida social. Dessa maneira,

If biography is presented as a dramatic summary of social needs and achievements, if the child's imagination pictures the social defects and problems that clamored for the man and the ways in which the individual met the emergency, then the biography is an organ of social study. (DEWEY, 1976, p. 106).

Tal concepção assemelha-se muito com o discutido e defendido por João Augusto de Toledo. Assim como Dewey, o professor destaca a necessidade de um ensino que se embase nas: conquistas, fracassos, lutas, vitórias; para que a criança possa relacionar com sua vida diária, ao mesmo tempo em que defende o estudo das biografias para que a compreensão dos grandes feitos por seres semelhantes à criança estimulem seu desenvolvimento e a necessidade de proporcionar "grandes feitos à sociedade". Fatores estes, que o lente destaca como fundamentais para o despertar do sentimento de pátria. Ou como Dewey (1976) destaca, promover a preparação da criança para a vida, procurando identificar-se e trazer inovações.

Outro aspecto que merece destaque refere-se à função do educador, João Augusto de Toledo (1918a, p.14) deixa claro, a necessidade de que o professor exija de seu aluno aquilo que ele pode oferecer, além de ajudar na melhor maneira de lidar com as crianças, porque "(...) querer tratar todos com iguais maneiras é absurdo como o é querer calçar a todos pela mesma fôrma".

O número 8, da Revista da Escola Normal de São Carlos ${ }^{13}$, traz o artigo, também de João Augusto de Toledo" ${ }^{14}$; denominado de "Os ideaes nacionaes e as escolas elementares" ${ }^{\text {", }}$ o autor destaca a necessidade de renovação da escola primária com base nos ideais pedagógicos modernos circundantes no momento. Afirma que o professor, além de ensinar leitura, escrita, cálculo, noções de geografia, de história e de ciências; precisa melhorá-lo enquanto entidade social e como produtor para que a criança possa por si só aplicar os conhecimentos adquiridos, cabendo à escola ligar-se a esta participação na vida social, “(...) pois não se educa um indivíduo para si mesmo, mas para viver em comunhão com os outros; para exercer, em certo meio, suas actividades, sem attritos com a actividade alheia”. (TOLEDO, 1920a, p. 05).

E continua sua discussão, destacando que de acordo com Dewey,

(...) affirmar-se que a educação é o desenvolvimento harmônico de todos os poderes do indivíduo. Não ha referencia apparente á vida social ou á cooperação della resultante, entretanto, tem-se esta como uma definição adequada e precisa dos fins da educação. Mas, si ella fôr tomada independentemente das relações sociaes, nós não teremos nem medida, nem critério para dizer o que significam os seus termos. Não sabemos o que seja poder, o que seja desenvolvimento, o que seja harmonia; um poder é um poder em relação ao uso que delle se faz, á funcção que preenche. Nada ha, na formação do ser humano, considerado isoladamente que forneça fins directores e sirva para designar poderes. Si abandonarmos o ideao decorrente da vida social, nada mais teremos sinão a vellha 'facilidade psychologica' para dizer-nos o que são poderes específicos e poder em geral. Ficariamos reduzidos a innumerar uma serie de faculdades, como percepção, memória, raciocínio, e affirmar que cada um destes poderes deve ser desenvolvido. Mas esta é uma affirmação estéril e formal. Reduz o treino a uma gymnástica vasia. Assim pensa Dewey. (TOLEDO, 1920a, p. 05) 
Desse modo, João Augusto de Toledo (1920a) finaliza ressaltando a necessidade de Escolas Normais harmonizadas com o mesmo intuito educacional, lendo, estudando cada vez mais para ajudar nas possíveis mudanças necessárias para se pensar a educação dos pequenos. Principalmente, no que se refere a considerar a vitalidade da alma infantil e esperar frutos desta, e não considerá-la como algo vazio a ser preenchido.

Com isso, nota-se que as ideias educacionais calcadas nas premissas do: aprender fazendo; cooperação; ocupações manuais ou trabalhos manuais; sociedade em miniatura ou comunidade embrionária; experiência; interesse; ensino ativo; educação ligada ao meio social; consideração das aptidões do sujeito; formação da moral; acabam se tornando jargões para se pensar uma nova educação, que aparecem defendidas e argumentadas por John Dewey em seus escritos. Essas premissas se tornaram fundamentais em nosso estudo, pois além de serem o centro das obras do autor, aparecem nos escritos e discussões dos lentes da Escola Normal de São Carlos-SP, como pudemos notar pela discussão feita nesse artigo. João Augusto de Toledo e Carlos da Silveira, lentes da instituição, são os educadores que se destacam por apresentarem em seus artigos a defesa dessas concepções, afirmando ser o ensino o caminho central na promoção do progresso ao país.

Com isso, pela análise dos artigos que compõem a Revista da Escola Normal de São Carlos-SP, pode-se constatar que os educadores brasileiros não estiveram alheios às novas propostas educacionais que emergiam, pelo contrário, mantiveram-se atentos e, apropriaram essas concepções em suas discussões em cunho nacional, visando propagar novas formas para se pensar a educação brasileira. Processo esse que ocorreu já no início do século XX, antes mesmo das primeiras traduções das obras de John Dewey realizadas por Anísio Teixeira e antes mesmo da eclosão do Movimento da Educação Nova no país, fatores que datam as décadas de 20-30.

\section{Considerações Finais}

As constatações feitas por meio desse estudo, portanto, nos permitem concluir que o filósofo John Dewey esteve presente nos debates e discussões promovidas no interior da Escola Normal Secundária de São Carlos-SP. Mesmo que sendo veiculadas por apenas dois educadores - Carlos da Silveira e João Augusto de Toledo - a apropriação de suas ideias se deu de forma ativa nas argumentações e proposições para uma nova forma de ensino às crianças. Desta forma, podemos afirma que John Dewey, no início da primeira metade do século XX, já tinha suas discussões apropriadas e refletidas na formação e proposições educativas da Escola Normal Secundária de São Carlos-SP, o que demonstra que suas ideias já se faziam presentes no território brasileiro, antes do Manifesto dos Pioneiros da Educação Nova de 1932, momento em que suas concepções foram divulgadas de forma mais intensa por meio das produções de nosso importante educador Anísio Teixeira. Entretanto este trabalho não se encerra aqui acreditamos que ele abre uma série de questionamentos a respeito deste movimento de apropriação que devem ser aprofundadas, porém, destacamos a riqueza que este periódico aqui analisado encerra em suas páginas sendo John Dewey apenas um dentre tantos outros a constituir o conjunto de saberes presentes na formação de professores em uma instituição do interior do Estado de São Paulo.

\section{Referências}

CUNHA, Marcus Vinícius da. John Dewey, Uma filosofia para educadores em sala de aula. Petrópolis: Vozes, 2002. 
DEWEY, John. Early Essays and Leibniz's new essays concerning the human understanding. In: DEWEY, John. The Early Works, 1882-1898. 2a Ed. Volume 01: 1882-1888. Sourthern Illinois University Press, 2008a.

Psychology. In: DEWEY, John. The Early Works, 1882-1898. Volume 02: 1887. Sourthern Illinois University Press, 1967.

Early Essays and Outlines of a critical theory of Ethics. In: DEWEY, John. The Early Works, 1882-1898. $2^{\text {a }}$ Ed. Volume 03: 1889-1892. Sourthern Illinois University Press, 2008b.

Early Essays. In: DEWEY, John. The Early Works, 1882-1898. 2a Ed. Volume 05: 1895-1898. Sourthern Illinois University Press, 2008c.

The School and Society. In: DEWEY, John. The Middle Works, 1899-1924. Volume 01: 1899-1901. Sourthern Illinois University Press, 1976. p.01-109.

. The Educational Situation. In: DEWEY, John. The Middle Works, 1899-1924. Volume 01: 1899-1901. Sourthern Illinois University Press, 1976. p.257-313.

. Schools of To-Morrow. In: DEWEY, John. The Middle Works, 1899-1924. Volume 08: 1915. Sourthern Illinois University Press, 1979. p.205-413.

MELO, Luis Correia de. Dicionário de Autores Paulistas. São Paulo: Gráfica Irmãos Andriole, 1954. (Comissão do IV Centenário da cidade de São Paulo).

MONARCHA, Carlos. Escola Normal da Praça: o lado noturno das luzes. Campinas: Editora Unicamp, 1999.

. Brasil arcaico, Escola Nova: ciência, técnica e utopia nos anos 1920-1930. São Paulo: Ed. Unesp, 2009.

Professor João Augusto de Toledo na Revista da Escola Normal de São Carlos: temas e motivos. In: ARCE, Alessandra; NERY, Ana Clara Bortoletto (Orgs). Ideias Pedagógicas em Movimento: Produção de saberes na Escola Normal de São Carlos. São Carlos: EdUFSCar, 2011.

NAGLE, Jorge. Educação e Sociedade na Primeira República. São Paulo: Editora da Universidade de São Paulo - EdUSP, 2009.

NEVES, Ary Pinto das. São Carlos na esteira do tempo. São Carlos: EdUFSCar, 2007.

PINHEIRO, Maria de Lourdes. Trajetória e interlocuções do educador paulista João Toledo (1900-1939): a permanência dos modelos de lição. DOUTORADO.

Universidade Estadual de Campinas - Faculdade de Educação - UNICAMP - Programa de Pós-Graduação em Educação. Campinas, 2009. Orientadora: Profa. Dra. Maria Cristina Menezes.

SAVIANI, Dermeval. História das Idéias Pedagógicas no Brasil. Campinas/SP: Autores Associados, 2007. (Coleção Memória da Educação). 
SOUZA, Rosa Fátima de. Templos de Civilização: A Implantação da Escola Primária Graduada no Estado de São Paulo (1890-1910). São Paulo: Editora Unesp, 1998.

TRUZZI, Oswaldo. Café e Indústria - São Carlos: 1850-1950. São Carlos: EdUFSCar, 2007.

\section{REVISTAS:}

Revista da Escola Normal de São Carlos, ano I, número 1, de 12 novembro de 1916.

Revista da Escola Normal de São Carlos, ano II, número 3, de 11 dezembro de 1917.

Revista da Escola Normal de São Carlos, ano III, número 4, de junho de 1918.

Revista da Escola Normal de São Carlos, ano III, número 5, de dezembro de 1918.

Revista da Escola Normal de São Carlos, ano IV, número 6, de junho de 1919.

Revista da Escola Normal de São Carlos, ano IV, número 7, de dezembro de 1919.

Revista da Escola Normal de São Carlos, ano V, número 8, de junho de 1920.

Revista da Escola Normal de São Carlos, anoV , número 9, de novembro de 1920

Revista da Escola Normal de São Carlos, ano VI, número 10, de junho de 1921.

Revista da Escola Normal de São Carlos, ano VI, número 11, de dezembro de 1921.

Revista da Escola Normal de São Carlos, ano VII, número 12, de dezembro de 1922.

Revista da Escola Normal de São Carlos, ano VIII, número 13 de dezembro de 1923.

Recebido em junho-12

Aprovado em fevereiro-13

Notas

\footnotetext{
${ }^{1}$ Doutoranda em Educação pelo Programa de Pós-Graduação em Educação da Universidade Federal de São Carlos - PPGE/UFSCar. Bolsista FAPESP. Mestre em Educação pelo Programa de Pós-Graduação em Educação da Universidade Federal de São Carlos - PPGE/UFSCar. Graduada em Pedagogia pela Universidade Federal de São Carlos - UFSCar.

${ }^{2}$ Professora do Departamento de Educação da Universidade Federal de São Carlos - UFSCar. Doutora em Educação Escolar pela UNESP de Araraquara e pós-doutora em História e Filosofia da Educação pela UNICAMP. Atualmente é bolsista produtividade em pesquisa pelo CNPq.

${ }^{3}$ Este trabalho é fruto de três outros trabalhos: o primeiro é um projeto de extensão intitulado: "Recuperação, Conservação e Organização do Acervo Documental e Bibliográfico da Escola Estadual Dr. Álvaro Guião", o segundo é o projeto de pesquisa intitulado "As Idéias Pedagógicas em Movimento na formação de professores na Escola Estadual Dr. Álvaro Guião (1930-1969) que contou com financiamento da Fundação de Amparo à pesquisa do Estado de São Paulo/FAPESP, e por fim integra os trabalhos de estudo e pesquisa que culminaram na produção da Dissertação de Mestrado "As Apropriações das ideias educacionais de John Dewey no interior da antiga Escola Normal Secundária de São Carlos -SP", como requisito para obtenção do título de Mestre em Educação pelo Programa de Pós-Graduação em Educação da Universidade Federal de São Carlos, financiado inicialmente pela CAPES e, posteriormente pela Fundação de Amparo à Pesquisa do Estado de São Paulo/FAPESP.

${ }^{4}$ Várias pesquisas vêm sendo desenvolvidas a partir do acervo desta escola Um exemplo de pesquisas já realizadas neste sentido são os seguintes trabalhos: NOSELLA, P. \& BUFFA, E. (2002) - Schola Mater. A antiga Escola Normal de São Carlos, 1911-1933- primeira reimpressão. São Carlos, EDUFSCar/FAPESP; SILVA, Emerson Correia da. A Configuração do Habitus Professoral para o Aluno-Mestre: A Escola Normal Secundária de São Carlos (1911-1923), dissertação de mestrado -Ano de Obtenção: 2009; SILVA, Emerson
} 
Correia da ; NERY, Ana Clara Bortoleto . O periódico Excelsior! (1911-1916) como ponto de observação do campo de formação de professores. Série-Estudos (UCDB), v. 26, p. 173-185, 2008; NERY, Ana Clara Bortoleto ; SILVA, Emerson Correia da. Associativismo Discente nas Escolas Normais do Brasil e de Portugal. Revista Educação e Cidadania, v. 5, p. 25-37, 2006; SILVA, Emerson Correia da . O professor ideal em Excelsior! (1911-1916): a revista dos alunos da Escola Normal de São Carlos. 1. ed. São Carlos/SP: Rima, 2007. v. 1. 96 p.; NERY, Ana Clara Bortoleto ; OZELIN, Jaqueline Rampeloti ; SILVA, Emerson Correia da ; INOUE, Leila Maria . Divulgando Práticas e Saberes: a produção impressa dos docentes das Escolas Normais do Brasil e Portugal (1911-1950). Marília/SP: M3T, 2007. v. 1; DIAS, Eneas B. Revista da Escola Normal de São Carlos (1916-1923): um estudo sobre idéias e práticas educacionais - dissertação de mestrado - 2009.

5 Atrelado ao Projeto Republicano de Educação Popular, os grupos escolares que eclodiram no final do século XIX e início do XX representaram a esperança de construção de uma nova nação, com base nesse novo regime em consolidação. Segundo Souza (1998), a escola primária tornou-se uma das principais, senão a principal divulgadora dos valores republicanos, por conseguinte, pode-se afirmar que esses grupos tornaram-se um símbolo ao país.

${ }^{6}$ Os lentes catedráticos, chamados de Doutores eram aqueles que ocupavam as matérias de ciências, letras e línguas, os demais que ficavam com as matérias auxiliares como: desenho, música, ginástica e trabalhos manuais, recebiam apenas a denominação de professores.

${ }^{7}$ Publicada de 1911 a 1916, a Revista Excelsior abrange os debates e discussões dos normalistas da Escola Normal Secundária de São Carlos em torno da transformação da sociedade brasileira que renascia no século $\mathrm{XX}$, por meio de novos ideais e aspirações. A grande ideia da revista, nesse sentido, é o de propagar e consolidar os ideais civilizadores por meio da ajuda de toda sociedade civil. Com o objetivo de elevar a classe docente e inseri-la nos debates educacionais nacionais em prol do desenvolvimento educacional, calcou-se no exercício de trabalhos literários e pedagógicos, visando a sua disseminação. Suas discussões englobam temas riquíssimos que vão desde a importância e configuração do Ensino Normal e Primário, como também as discussões pedagógicas, buscando debater as concepções circundantes e defender meios mais eficazes de consolidação do processo educativo.

${ }^{8}$ Vale ressaltar, que essas são compostas por todos os trabalhos realizados por John Dewey ao longo de sua vida. Por isso, além dos estudos organizados nas duas primeiras coleções: "The Early Works" (1882-1898)" e “The Middle Works (1899-1924)"; encontra-se uma outra coleção: "The Later Works (1925-1953)", a qual devido a cronologia de nosso estudo (1916-1923), não foi nosso objeto de análise.

${ }^{9}$ Tal cadeira de Psicologia Experimental, segundo Monarcha (1999) vem em decorrência da influência do comtismo e no clima da belle époque que se instaurara no país, época na qual as ideias de Darwin e Spencer se tornam as bases estruturantes do processo educativo. Desta forma, busca-se integrar a Pedagogia aos campos dos conhecimentos em expansão: psicologia fisiológica, antropologia e antropométrica. Com a reforma das escolas normais secundárias em 1912, foi constituído um núcleo pedagógico com a entrada de três cadeiras: $11^{\mathrm{a}}$ e $12^{\mathrm{a}}$ denominadas de Psicologia Experimental, Pedagogia e Educação Cívica; e a $13^{\mathrm{a}}$ de Métodos e Processos de Ensino, Crítica Pedagógica e Exercícios do Ensino; cadeiras estas formadas pelos princípios que emergiram a partir das propostas de medição da inteligência veiculadas por Ugo Pizzoli, e concretizadas por Clemente Quaglio, na Escola Normal da Praça.

${ }^{10}$ Ambos os lentes tiveram a oportunidade de aprofundar seus estudos sobre a Pedagogia Científica proposta por essas cadeiras em um curso ministrado por Ugo Pizzoli, na Escola Normal da Praça, no ano de 1914 e, assim, puderam trazer as ideias veiculadas pela mesma para a Escola Normal de São Carlos.

${ }^{11}$ As informações contidas neste tópico foram retiradas dos seguintes trabalhos: Pinheiro, Maria de Lourdes. Trajetória e interlocuções do educador paulista João Toledo (1900-1939): a permanência dos modelos de lição. Tese de Doutorado. Unicamp: 2009; MONARCHA, Carlos. Professor João Augusto de Toledo na Revista da Escola Normal de São Carlos: temas e motivos. In: ARCE, Alessandra; NERY, Ana Clara Bortoletto.(orgs). Ideias Pedagógicas em Movimento: Produção de saberes na Escola Normal de São Carlos. São Carlos: EdUFSCar, 2011.

${ }^{12}$ Revista da Escola Normal de São Carlos - SP. Anno 5 - Número 9, Novembro de 1920. (1920b).P. 33-49.

${ }^{13}$ Revista da Escola Normal de São Carlos - SP. Anno 4 - Número 8, Junho de 1920. (1920a).

${ }^{14}$ Lente da $12^{\mathrm{a}}$ cadeira.

${ }^{15}$ Revista da Escola Normal de São Carlos - SP. Anno 4 - Número 8, Junho de 1920. (1920a). P. 3-20 